\title{
MICROENCAPSULATION OF NATURAL POLYPHENOLIC COMPOUNDS EXTRACTED FROM APPLE PEEL AND ITS APPLICATION IN YOGHURT
}

\author{
Tamer Mohammed El-Messery ${ }^{1 凶}$, Marwa M. El-Said ${ }^{1}$, Evren Demircan², \\ Beraat Ozçelik ${ }^{2}$
}

${ }^{1}$ Dairy Department, National Research Centre, Egypt

${ }^{2}$ Food Engineering Department, Istanbul Technical University

Maslak, 34469, Istanbul, Turkey

\begin{abstract}
Background. Apple peel is a by-product of fruit processing and a rich source of natural antioxidants, especially of polyphenolic compounds. Although it has many health benefits, the microencapsulation of polyphenolic compounds protects it from reactions with milk components during manufacturing or storage of dairy products which reduce the bioavailability and total acceptability of these products.

Materials and methods. Polyphenolic compounds (PC) were extracted from apple peel using ethanol (80\%). Polyphenolic compounds extract powder (PCEP) was encapsulated by physical methods (spray and freeze dryer) using maltodextrin, whey protein concentrate (8:2), and Gum Arabic mixture (6:4) as coating materials, which were homogenized by ultraturrax and ultrasonication. Encapsulated PCEP was used in supplementing yoghurt. Phenolic content (PC), physiochemical and texture properties of yoghurt samples were evaluated during storage (fresh, 7 and 15 days).

Results. The microencapsulation by freeze dryer method for PCEP which was homogenized by ultrasonication was the best treatment, while encapsulation efficiency using the spray dryer method, which was homogenized by ultraturrax, was the worst. Encapsulated PCEP in yoghurt samples didn't have any significant influence on the physiochemical and texture properties of these samples.

Conclusion. Yoghurt samples maintained on the polyphenolic compounds until the end of storage overall, our results revealed that adding encapsulated PCEP into yoghurt gave closer characteristics to the control sample.
\end{abstract}

Keywords: apple peel, polyphenolic compounds, microencapsulation yoghurt, spray and freeze dryer

\section{INTRODUCTION}

Apples (Malus pumila) are used commonly in human nutrition due to their availability throughout the year and a pleasant taste. They also contain many nutrients, such as vitamins, minerals and other bioactive components. Peels and seeds are the major by-products of fruit processing and they contain high amounts of phenolic compounds (PC), flavonoids and antioxidants compared to whole fruit (Ajila et al., 2007;
Vieira et al., 2009). Natural phenolic compounds are receiving a lot of attention due to their potential beneficial health properties (Bueno et al., 2012). An apple has $80 \%$ of its PC concentrated in the peel, and fiveto-six-fold the antioxidants in the apple peel than in the flesh (Leccese et al., 2009). The increasing health awareness of consumers has created a great demand for functional foods containing PC (Sun-Waterhouse 
et al., 2010; 2012a; 2013a). Yoghurt is one common dairy functional food that presents dietary delivery systems for PC. It is known that PC are sensitive ingredients and their application in foods presents challenges due to their stability whether during food processing or storage (Sun-Waterhouse et al., 2010; 2012a; 2013a). Encapsulation technology can solve this problem, where encapsulation protects bioactive ingredients like PC from damage during food processing (Sun-Waterhouse et al., 2012b). Freeze and spraydrying are the most applied physical encapsulation techniques, both of which depend on water being removed, either by sublimation of the frozen product or by conversion of the performance of the product from solution to powder using a continuous feeding process in a hot drying medium, respectively (Gharsallaoui et al., 2007). The advantage of the freeze-drier technique is that the product components aren't exposed to high temperatures, which can maintain the nutritious characteristics of the product. On the other hand, the spraydrying technique is very suitable for any product in a liquid state (Do Espírito Santo et al., 2013). It is important to choose the coating materials which are used in the encapsulation process because it may affect encapsulation efficiency and the capsule's stability. There is a wide range of coating materials used in the encapsulation process, such as dextrin, Gum Arabic, gelatin, starch and whey protein (Fang and Bhandari, 2010). The most common coating material used in encapsulating is maltodextrin (MD) because it has a low bulk density and viscosity, is easy to form films from, and creates a barrier to oxygen (Rai et al., 2016). Another polysaccharide commonly used in encapsulation processes is Gum Arabic because it has a high capacity for forming a good emulsifier and film (Silva et al., 2013). Whey protein (WP) is a by-product of the dairy industry which is commonly used in the food industry because it has a high nutritional value and the physiochemical properties of (emulsion, stabilization and gel formation).

The aim of this study is production of yoghurt supplemented with encapsulated PC extracted from apple peel by using two different encapsulation techniques: freeze and spray-drying.

\section{MATERIALS AND METHODS}

\section{Materials}

Apples (Amasya) were bought from a local market in Istanbul, Turkey. Skimmed milk powder (low heat), was made in the USA. Starter strains of Streptococcus thermophiles and Lactobacillus delburkii ssp. bulgaricus were obtained from stock cultures of a Microbiology laboratory of the Food Engineering Department in Istanbul Technical University, Turkey. Maltodextrin, whey protein concentrate $(80 \%)$ and Gum Arabic were purchased from Alfasol Co., Turkey. Folin-Ciocalteu reagent, Gallic acid and 1,1-diphenyl-2-pycrylhydrazyl (DPPH) were purchased from Sigma-Aldrich Co. (St. Louis, USA). All solvents were used in HPLC grade.

\section{Preparation of apple peel}

Apples were selected free from bruises and visual defects then washed with flowing water and peeled. The apple peel was collected and stored in a freezer $\left(-18^{\circ} \mathrm{C}\right)$ until used. The method of Grigoras et al. (2013) was used for preparation of the apple peel extracts with slight modifications. $1 \mathrm{~g}$ of freeze dried and ground powder of apple peel was extracted by $20 \mathrm{ml}$ ethanol $(80 \%)$ and exposed to an ultrasonic bath at $25^{\circ} \mathrm{C} / 20 \mathrm{~min}$. All extractions were centrifuged at $5000 \mathrm{rpm}$ for $10 \mathrm{~min}$ and the supernatant removed. A rotary evaporator (Büchi R20, Switzerland) was used at $40^{\circ} \mathrm{C}$ until the volume decreased and all ethanol was removed. The treatments were repeated three times, then the concentration was frozen at $-20^{\circ} \mathrm{C}$ overnight and then dried using a freeze dryer (Christ Alpha 1-2LD plus, Germany). The temperature of the ice condenser and the vacuum pressure were set to $-50^{\circ} \mathrm{C}$ and $0.04 \mathrm{mbar}$, respectively. After running the freeze-drying process for $72 \mathrm{~h}$, the dried product was collected, pulverized and stored in an airtight container for further analysis.

\section{Identification of phenolic and flavonoid compounds}

UHPLC analysis. A Shimadzu LC-10A apparatus (Kyoto, Japan) equipped with a SPD-M10A photodiode array detector (PDA) was used for analytical UHPLC separations. Reversed-phase chromatography 
was performed with a $250 \times 4.6 \mathrm{~mm}$ Kromasil 100 C-18 column packed with $5 \mu \mathrm{m}$ particles (teknokroma, Barcelona, Spain), fitted with a security guard C18 ODS $(4 \times 3.0 \mathrm{~mm}$ i.d. $)$. Gradients were formed with a He-degassed solvent. Solvent A was $\mathrm{H} 2 \mathrm{O}$ containing $0.1 \%$ formic acid, and solvent $\mathrm{B}$ was $\mathrm{MeCN}$ by applying different elution conditions. Separation was accomplished starting with $5 \% \mathrm{~A}$ for $2 \mathrm{~min}$ at pressure of $115 \mathrm{bar}$, followed by a linear gradient performed for $10 \mathrm{~min}$ from $5 \% \mathrm{~B}$ to $95 \% \mathrm{~A}$ and subsequent linear gradients from $20 \%$ to $95 \% \mathrm{~A}$ in $5 \mathrm{~min}$. The flow rate was $0.5 \mathrm{ml} \cdot \mathrm{min}^{-1}$, and the operating temperature was $40^{\circ} \mathrm{C}$. The injection volume was $10 \mu$ l. The chromatogram was recorded at $286 \mathrm{~nm}$.

Encapsulation procedure. Polyphenolic compounds extract powder - PCEP was encapsulated with three different coating materials. The first wall material was MD : WPC at ratio $8: 2$ then PCEP was added $(1: 20)$. An Gum Arabic mixture (second wall material) was added to the previous mixture at ratio $4: 6$. This mixture was exposed to two different homogenization methods: high-speed homogenizer (ultraturrax) at $4000 \mathrm{rpm}$ for $5 \mathrm{~min}$ and ultrasonication $(160 \mathrm{~W}$ power, $20 \mathrm{KHz}$ frequency and with $50 \%$ pulse, Sonic Ruptor 400 , OMNI International the Homogenizer Company, GA, USA). Then the mixtures were dried using two methods: freeze drying for $48 \mathrm{~h}$ and spray drying. The spray dryer (March Cool Industry Co., Ltd., Bangkok, Thailand) was operated at an inlet temperature of $150^{\circ} \mathrm{C}$ and an outlet temperature of $50^{\circ} \mathrm{C}$. For the freeze-drying process, the mixtures were placed in freezing trays and frozen at $-20^{\circ} \mathrm{C}$ immediately after preparation. After $24 \mathrm{~h}$, the frozen mixtures were dried for more than $48 \mathrm{~h}$ at $-45^{\circ} \mathrm{C}$ under a pressure of less than 0.120 mbar using a freeze dryer (Model 7948030 , Labconco, USA). The spray-dried and freeze-dried samples were kept at $-18^{\circ} \mathrm{C}$ for further analysis. At the time of use, the dried content was ground into a fine powder. Each experiment was triplicated.

\section{Encapsulation characterizations}

Encapsulation efficiency (EE). Encapsulation efficiency (EE \%) was calculated by determination phenolics content (PC), antioxidant activity (AA) and total flavonoids (TF) before and after encapsulation. Five grams of sample were dissolved in ethanol $(70 \%$ $\mathrm{v} / \mathrm{v}$ ) for $5 \mathrm{~min}$ and the quantities of TPC, AA and TF were determined as mean values and triplicate measurements (Ades et al., 2012; Fernandes et al., 2014).

Phenolics and flavonoids content. Phenolics content (PC) was measured using a Folin-Ciocalteu assay (Wollgast and Anklam, 2000) while flavonoids content (FC) was recorded according to the method described by Lee et al. (2003). The results were expressed as $\mathrm{mg}$ of catechin equivalents (CE) per kg of defatted samples. All samples were analysed in triplicate.

DPPH-radical scavenging activity assay. DPPH-radical scavenging activity was determined according to the method introduced by Kumaran and Karunakaran (2006) and Rai et al. (2006). $0.1 \mathrm{mM}$ of DPPH was prepared by dissolving $3.943 \mathrm{mg}$ DPPH in $100 \mathrm{ml}$ ethanol. $100 \mu \mathrm{l}$ of each sample was mixed with $2 \mathrm{ml}$ methanolic solution of DPPH (0.1 mM). Extracts were substituted with methanol and distilled water blanks. Decolorization of purple free radical DPPH solution was measured at $517 \mathrm{~nm}$ after 30 min incubation in the dark and at room temperature. The antioxidant activity was calculated by using the following equation:

Antioxidan activity, $\%=\frac{\text { control }- \text { sample }}{\text { control }} \times 100$

Surface morphology analysis. Particle structures of PCEP capsules were evaluated by scanning Electron Microscopy (Quanta FEG 250 SEM; Thermo Fisher Scientific, Oregon, USA), which was used to acquire the morphology of microcapsule powder at an accelerating voltage of $10.0 \mathrm{kV}$. Polyphenolic compound extract powder - PCEP microcapsule samples were sprinkled onto an adhesive coated aluminum pin stub. The stubs were sputter coated with a thin layer of gold in a Leica vacuum coating unit at $40 \mathrm{~mA}$ for $100 \mathrm{~s}$ 3 times, at a working distance of $50 \mathrm{~mm}$ by using an argon gas purge (Quorum SC7620 Sputter Coater). Digital images were taken at a magnification of $4000 \times$, and 12,000× (Ferreira et al., 2007a).

Measurements of particle size distribution and zeta potential. The particle size and zeta potential 
were determined with a dynamic light scattering instrument (Nano ZS, Malvern Instruments, Worcestershire, UK).

Yoghurt preparation. Skimmed milk powder (12\%) was reconstituted in distilled water. Polyphenolic compound extract powder was used to replace total solids of SMP at ratios 5, 10, 15 and $20 \%$. All samples were subjected to pasteurization $\left(85^{\circ} \mathrm{C}\right.$ for $\left.30 \mathrm{~min}\right)$ and cooled directly to $45^{\circ} \mathrm{C}$ before being inoculated with starter bacteria ( $S$. thermophiles and Lb. delburkii ssp. bulgaricus) at 3\%. The previous samples were incubated at $42^{\circ} \mathrm{C}$ until the curd formed then stored in a refrigerator at $5 \pm 2^{\circ} \mathrm{C}$.

\section{Physicochemical characteristics of yoghurt} pH and titratable acidity measurement. $\mathrm{pH}$ was measured by a $\mathrm{pH}$ meter (JENWAY 3505) equipped with a combined electrode. Titratable acidity of the yoghurt was measured according to the 942.15 AOAC (2000), and results were expressed as lactic acid \%.

Color measurement. Hunter LAB (Color quest XE, Hunter Lab, USA) was used to analyze the color of yoghurt samples. Illuminant D65 was the source of light and the observation was 10 degrees. The color value was evaluated as $L^{*}$ (lightness), $a^{*}$ (negative value means green and positive value means red), and $b^{*}$ (negative value means blue and positive value means yellow). All samples were done in triplicate.

Apparent viscosity. A dynamic viscometer (Brookfield Model-LV; Brookfield Engineering Laboratory, Stoughton, USA) was used at a speed of $100 \mathrm{rpm}$. All the assays were performed in triplicate.

\section{Statistical analyses}

The data obtained in this study was expressed as the mean of triplicate determinations. Statistical comparisons were made with Duncan's test which was analyzed with SPSS (SPSS for Windows, Version Rel. $10.0 .5,1999$, SPSS Inc.). $P$-values $<0.05$ were considered to be significant.

\section{RESULTS AND DISCUSSION}

\section{Identification of phenolic and flavonoid compounds by UHPLC}

The HPLC method was used to determine the individual PC from the apple peel. Sixteen phenolic compounds used as standards are listed, with retention times and absorbance ratios. All the standards used were determined by their spectral properties Table 1 and Figure 1. The highest amount of $\mathrm{PC}$ in the apple peel was phloridzin $\left(321.28 \mathrm{mg} \cdot \mathrm{kg}^{-1}\right)$. Balázs et al. (2012) and Jakobek et al. (2013) stated that flavanols and anthocyanins are characteristic compounds of apple peel. The total value of identified PC was $1141.92 \mathrm{ppm}$ and this can be confirmed by Jakobek et al. (2013) who mentioned PC in apple peel ranged from 672 to $3150 \mathrm{mg} \cdot \mathrm{kg}^{-1}$.

Table 1. UHPLC of PC identified in apple peel

\begin{tabular}{|c|c|c|}
\hline Phenolics group & $\begin{array}{l}\text { Retention } \\
\text { time }\end{array}$ & $\begin{array}{c}\text { Concentration } \\
\text { of phenolic } \\
\text { compounds } \\
\mathrm{mg} / \mathrm{kg}\end{array}$ \\
\hline 1 4-hydroxybenzoic acid & 10.328 & 0.55 \\
\hline 2 Gallic acid & 13.99 & 120.03 \\
\hline 3 3,4-dihydroxybenzoic acid & 15.68 & 8.46 \\
\hline 4 Unknown & 15.756 & \\
\hline 5 Catechin & 16.151 & 88.27 \\
\hline 6 Rutin & 16.496 & 77.20 \\
\hline 7 Chlorogenic acid & 17.003 & 68.24 \\
\hline 8 Unknown & 17.067 & \\
\hline 9 Unknown & 17.201 & \\
\hline 10 Ferulic acid & 18.058 & 102.51 \\
\hline 11 Caffeic acid & 18.224 & 126.27 \\
\hline 12 Phloridzin & 18.568 & 321.28 \\
\hline 13 p-coumaric acid & 18.795 & 0.62 \\
\hline 14 Ethyl 3,4-dihydroxybenzoat & 19.531 & 18.21 \\
\hline 15 Quercetin & 19.604 & 93.90 \\
\hline $16 \mathrm{t}$-cinnamic acid & 20.866 & 116.38 \\
\hline
\end{tabular}




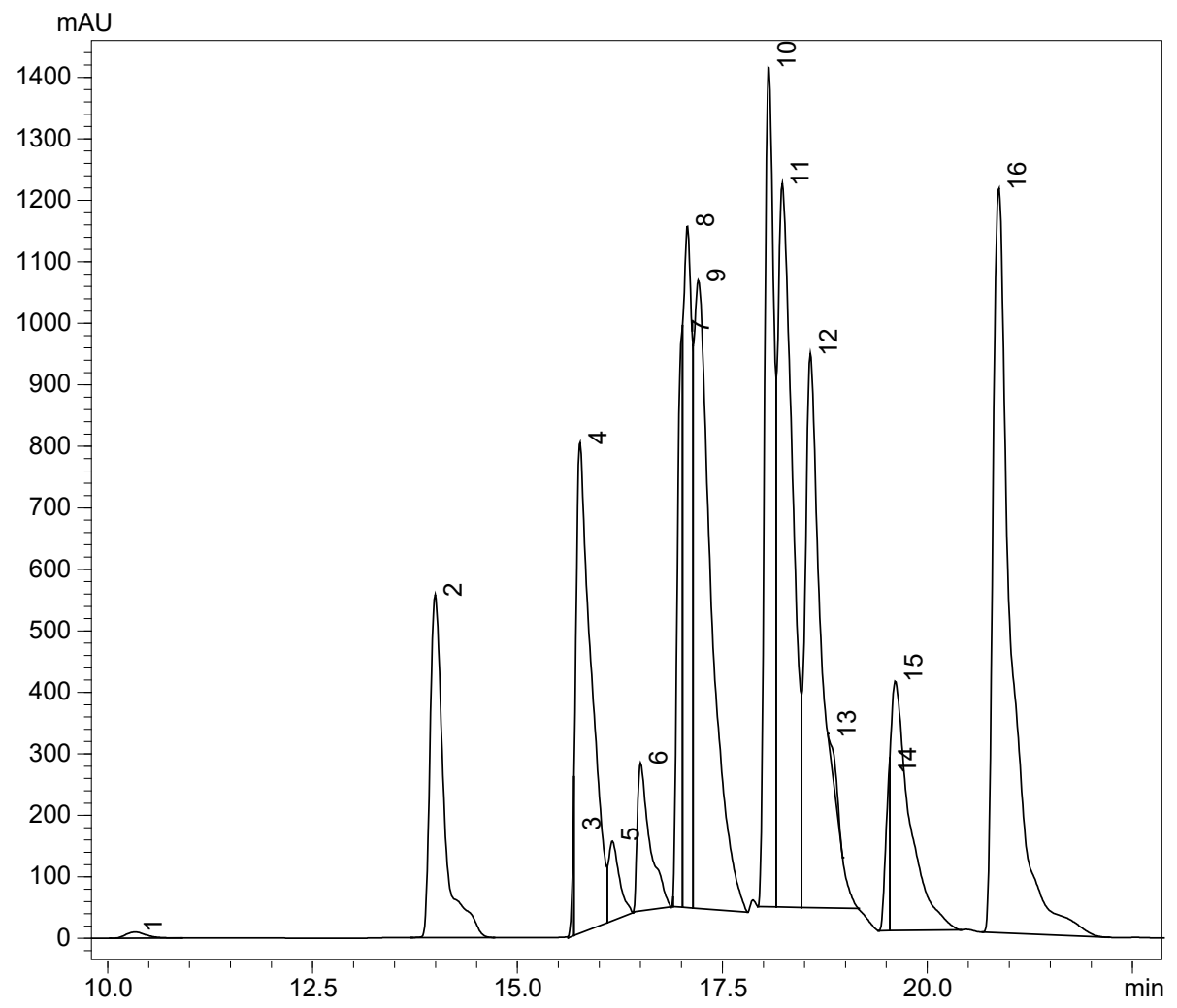

Fig. 1. UHPLC of PC identified in apple peel

Table 2. Particle size and zeta potential of encapsulated PCEP

\begin{tabular}{lccc}
\hline Treatments & Particle size, $\mathrm{n}$ & PdI & Zeta potential, $\mathrm{mV}$ \\
\hline Ultraturrax & $719.07 \pm 61.554$ & $0.441 \pm 0.013$ & $-27.633 \pm 0.208$ \\
Ultrasonic & $315.500 \pm 26.212$ & $0.416 \pm 0.038$ & $-28.833 \pm 0.153$ \\
\hline
\end{tabular}

\section{Particle size and zeta potential}

Table 2 shows the particle size and zeta potential for PCEP and the wall materials mixture which was homogenized by ultrasonic and ultraturrax. The results of particle size and zeta potential referred to use ultrasound for $20 \mathrm{~min}$ in encapsulation let to decrease the size of capsules than capsules formed by ultraturrax and this is due to increase the energy density and time sonication where lead to form particles with small size and more disruption and stabilized (Delmas et al., 2011).

\section{Encapsulated characterizations}

Encapsulated efficiency (EE). Figure 2 shows the encapsulated efficiency (EE) of encapsulated PCEP by using two different encapsulation techniques (freeze drying and spray drying) and two different homogenization methods (ultrasonication and ultraturrax). The results revealed that EE values were higher when freeze drying and ultrasonication were used than when using spray drying and ultraturrax. Under these conditions, the EE values of encapsulated PCEP were $86.85 \%, 83.69$ and $85.47 \mathrm{mg}$ catechin $/ \mathrm{kg}$ for AA, PC 


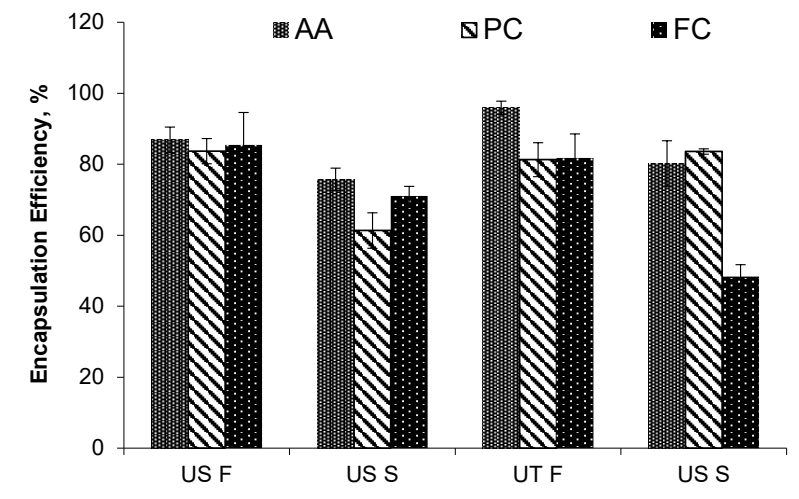

Fig. 2. EE\% of encapsulated PCEP using freeze-drying (F), spray drying (S) US and homogenized by ultraturrax and ultrasonication: US F - freeze drying homogenized by ultrasonication, UT F - freeze drying homogenized by ultraturrax, US S - spray drying homogenized by ultrasonication, UT S - spray drying homogenized by ultraturrax

\section{A}

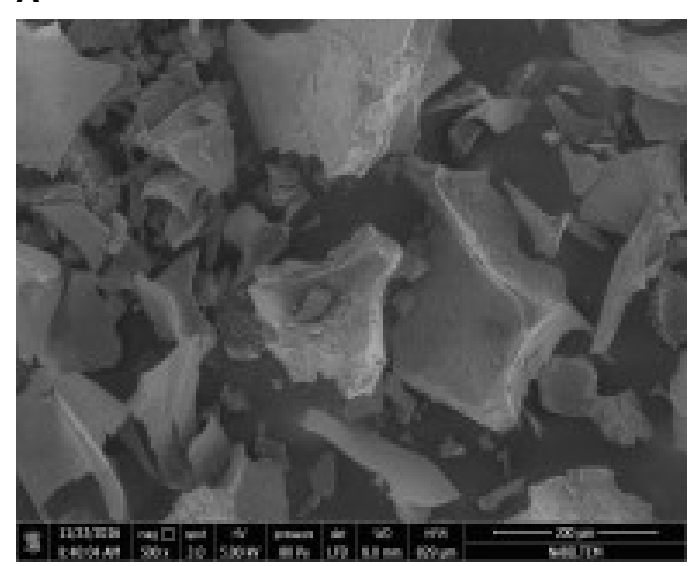

C

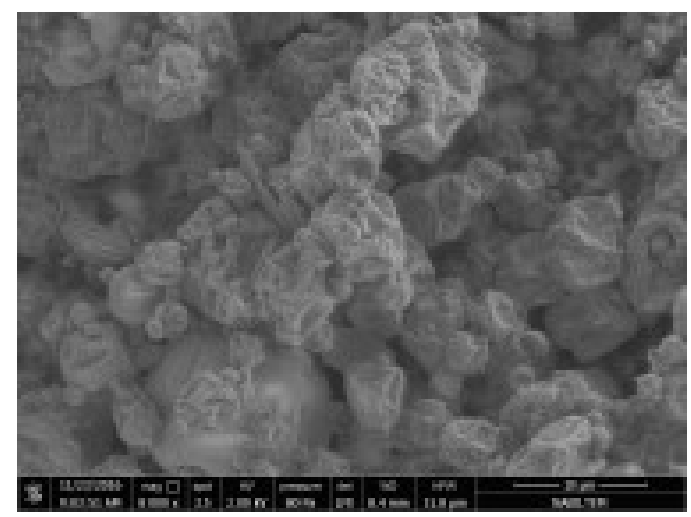

and FC respectively when encapsulated by freeze drying and using ultrasonication, while EE values were $80.21 \%, 83.58 \%$ and $48.31 \% \mathrm{mg}$ catechin $/ \mathrm{kg}$ for AA, TPC and TF respectively when encapsulated by spray drying and using ultraturrax. These results agree with Ramírez et al. (2015), who reported that the encapsulated efficiency was high when subjected to freezedrying and TPC, AA, and TF are retained within the capsule matrix at a high ratio. Chen et al. (2013) and Dickinson et al. (2003) reported that spray drying forms microcapsules at the last stage of the drying process and this leads to a high incidence of entrapment of extract content and a decreasing of surface content. In contrast, freeze drying allows droplet-to-droplet interaction in the extract until the drying stage and this leads to a higher consumption of time than spray

\section{B}

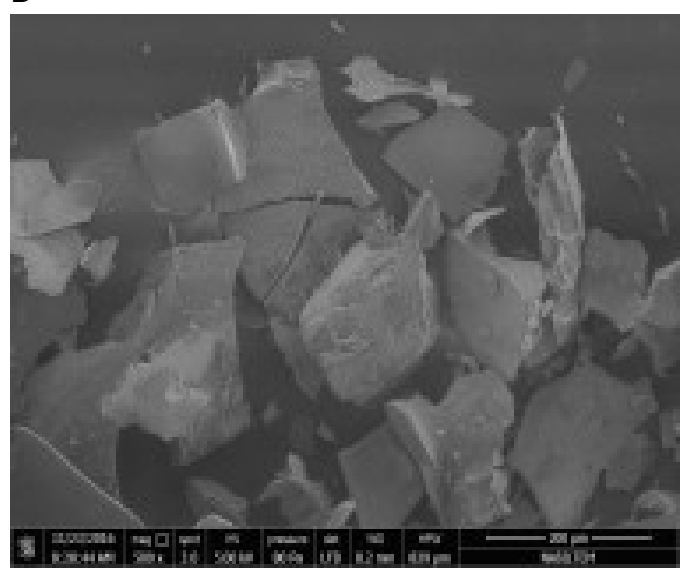

D

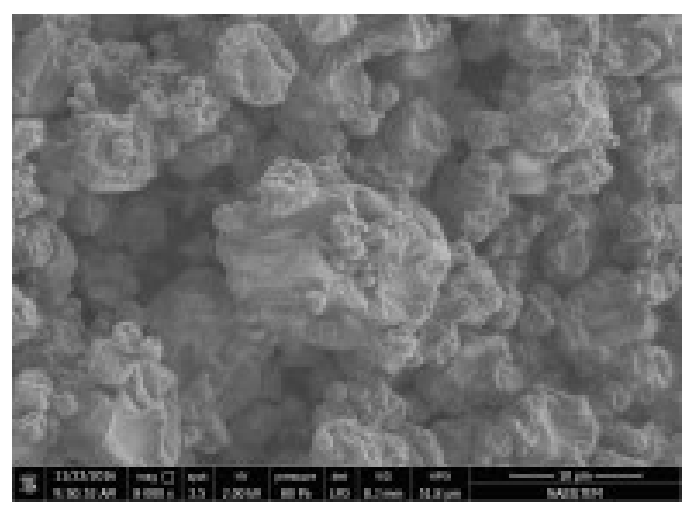

Fig. 3. SEM of encapsulated PCEP particles by freeze-drying and spray-drying and homogenized by ultrasonication and ultraturrax: A - freeze drying and ultraturrax, B - freeze drying and ultrasonication, $\mathrm{C}$ - spray drying and ultraturrax, $\mathrm{D}$ - spray drying and ultrasonication 
drying, resulting in an inconsistency in the entrapment of the extract of the freeze-dried encapsulated powder which leads to a low incidence of entrapment of extract content and thereby, a high surface content.

Scanning electron microscope (SEM). The images of the particle structure for samples encapsulated by freeze-drying and spray-drying techniques are shown in Figure 3. Scanning electron microscope of encapsulated samples revealed that the freeze-dried powder seemed to have sharper edges, a broken glass-like surface, and a brittle texture which was due to a lyophilized process and a longer drying period (Khazaei et al., 2014). Sahin-Nadeem et al. (2013) mentioned that the outer topography of the spray dried particles was a spherical shape with a shallow dent of shrinkage and without cracks or pores, resulting from the protein in the wall material. The absence of pores/cracks on the particle surface is very important for preventing the inward diffusion of oxygen and hence for better protection of the encapsulated extract. Moreover, this significantly enhanced the oxidative stability of spray dried microcapsules compared to freeze dried ones, which is partly due to a lower overall surface area and a lower surface extract content.

pH and titratable acidity (TA). The changes in $\mathrm{pH}$ and acidity of yoghurt samples during 15 days of storage at $4^{\circ} \mathrm{C}$ are shown in Table 3. The $\mathrm{pH}$ values in yoghurt samples containing encapsulated PCEP, fresh and after 15 days, was lower than in the control sample while it decreased after 15 days during cold storage for all samples $(P<0.05)$. On the other hand, TA of the control sample was lower than yoghurt samples fortified with encapsulated PCEP when fresh and after 15 days of storage, and these values were increased during cold storage for all samples. This increase in TA indicates that microorganisms are more active in the presence of encapsulated PCEP (Kailasapathy et al., 2000).

\section{Color analysis of yoghurt supplemented with dif-} ferent concentrations of encapsulated PCEP. Color plays an important role in the food choice of consumers. Table 4 shows the measurement of yoghurt color in terms of lightness $(L)$, red-green axis $\left(a^{*}\right)$ and yellow-blue axis $\left(b^{*}\right)$. Color characteristics for yoghurt samples ranged from $88.380 \pm 0.168$ to $75.807 \pm 0.040$ for lightness $\left(L^{*}\right),-4.193 \pm 1.276$ to $1.360 \pm 0.000$ for redness $\left(a^{*}\right)$, and $8.600 \pm 1.433$ to $12.203 \pm 1.218$ for yellowness $\left(b^{*}\right)$. From these results, lightness $\left(L^{*}\right)$ values of the control sample were higher than other samples. Whiteness in plain yoghurt results from the presence of colloidal particles, such as milk fat globules and casein micelles, capable of scattering light in the visible spectrum (Fox and McSweeney, 1998). The samples fortified with encapsulated PCEP have lower lightness than the plain yoghurt due to the presence of pigments in PCEP such as anthocyanin, which agrees with Hashim et al. (2009). The $a$ value (redness) significantly decreased for yoghurt samples fortified with encapsulated PCEP, whereas the $b$ value (yellowness)

Table 3. $\mathrm{pH}$ and TA of yoghurt samples supplemented with different concentrations of encapsulated PCEP

\begin{tabular}{lcccccc}
\hline \multirow{2}{*}{$\begin{array}{c}\text { Concentrations } \\
\text { of encapsulated } \\
\text { PCEP, \% }\end{array}$} & \multicolumn{3}{c}{ Titratable acidity - TA, \% } & \multicolumn{2}{c}{ PH } \\
\cline { 2 - 7 } & storage period, day & 7 & 15 & fresh & 7 & \multicolumn{2}{c}{ storage period, day } \\
\cline { 2 - 7 } Control & $0.90 \pm 0.014^{\mathrm{b}}$ & $0.92 \pm 0.021^{\mathrm{b}}$ & $0.97 \pm 0.014^{\mathrm{b}}$ & $4.66 \pm 0.0141^{\mathrm{a}}$ & $4.61 \pm 0.014^{\mathrm{a}}$ & $4.59 \pm 0.0141^{\mathrm{a}}$ \\
5 & $0.93 \pm 0.014^{\mathrm{b}}$ & $0.95 \pm 0.014^{\mathrm{b}}$ & $0.98 \pm 0.014^{\mathrm{b}}$ & $4.63 \pm 0.0141^{\mathrm{a}}$ & $4.59 \pm 0.021^{\mathrm{b}}$ & $4.55 \pm 0.0141^{\mathrm{a}}$ \\
10 & $0.96 \pm 0.007^{\mathrm{b}}$ & $0.99 \pm 0.007^{\mathrm{b}}$ & $1.12 \pm 0.021^{\mathrm{a}}$ & $4.61 \pm 0.0141^{\mathrm{a}}$ & $4.56 \pm 0.014^{\mathrm{b}}$ & $4.51 \pm 0.0141^{\mathrm{a}}$ \\
15 & $0.98 \pm 0.021^{\mathrm{b}}$ & $1.11 \pm 0.014^{\mathrm{a}}$ & $1.14 \pm 0.021^{\mathrm{a}}$ & $4.58 \pm 0.0141^{\mathrm{b}}$ & $4.51 \pm 0.014^{\mathrm{b}}$ & $4.46 \pm 0.0141^{\mathrm{b}}$ \\
20 & $1.05 \pm 0.078^{\mathrm{a}}$ & $1.13 \pm 0.021^{\mathrm{a}}$ & $1.16 \pm 0.014^{\mathrm{a}}$ & $4.54 \pm 0.0071^{\mathrm{b}}$ & $4.49 \pm 0.021^{\mathrm{b}}$ & $4.43 \pm 0.0071^{\mathrm{b}}$ \\
\hline
\end{tabular}

Means with different superscripts column $(\mathrm{a}, \mathrm{b}, \mathrm{c})$ differ significantly $(P<0.05)$ from each other. 
Table 4. Color parameters of fresh yoghurt samples supplemented with different concentrations of encapsulated of PCEP

\begin{tabular}{lccc}
\hline $\begin{array}{c}\text { Concentrations } \\
\text { of PCEP, } \%\end{array}$ & $L^{*}$ & $a^{*}$ & $b^{*}$ \\
\hline Control & $88.380 \pm 0.168^{\mathrm{a}}$ & $-4.193 \pm 1.276^{\mathrm{e}}$ & $8.600 \pm 1.433^{\mathrm{d}}$ \\
5 & $88.503 \pm 0.006^{\mathrm{a}}$ & $-3.427 \pm 1.241^{\mathrm{d}}$ & $8.600 \pm 0.017^{\mathrm{d}}$ \\
10 & $85.473 \pm 0.202^{\mathrm{b}}$ & $-2.850 \pm 0.736^{\mathrm{c}}$ & $9.433 \pm 0.586^{\mathrm{c}}$ \\
15 & $83.923 \pm 0.078^{\mathrm{c}}$ & $-1.287 \pm 0.771^{\mathrm{b}}$ & $10.380 \pm 0.661^{\mathrm{b}}$ \\
20 & $79.277 \pm 0.126^{\mathrm{d}}$ & $0.153 \pm 0.975^{\mathrm{a}}$ & $10.200 \pm 1.001^{\mathrm{a}}$ \\
\hline
\end{tabular}

$L^{*}$ - lightness, $a^{*}$ - negative value means green and positive value means red, $b^{*}$ - negative value means blue and positive value means yellow.

Means with different superscripts column $(\mathrm{a}, \mathrm{b}, \mathrm{c})$ differ significantly $(P<0.05)$

from each other.

increased. The $a$ value (redness) decreased from 4.193 \pm 1.276 (plain yoghurt) to $1.360 \pm 0.000$ with the addition of up to $5 \%$ encapsulated PCEP, whereas the $b$ value (yellowness) increased significantly. Increasing the amount of encapsulated PCEP in yoghurt gave it a more yellowish color, which agrees with Chung et al. (2010).

Apparent viscosity. The viscosity of plain yoghurt with encapsulated PCEP was determined with a viscometer as shown in Figure 4. The viscosity of yoghurt with added PCEP decreased significantly compared

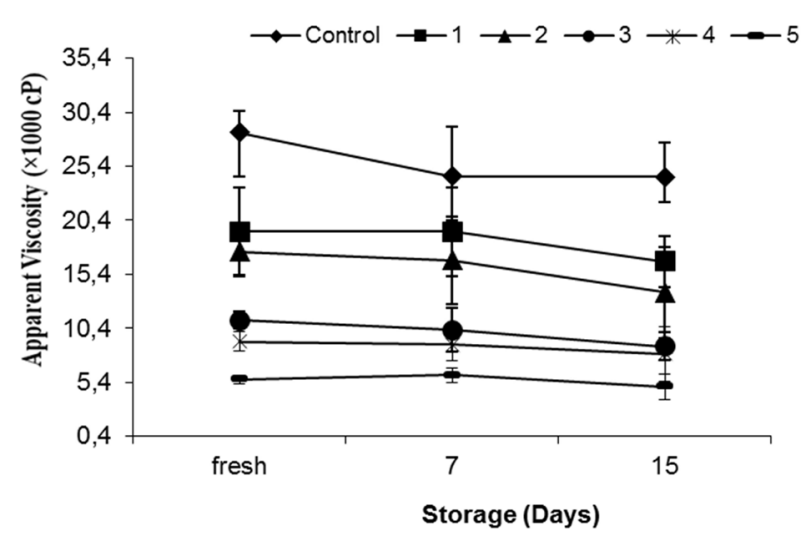

Fig. 4. Apparent viscosity of yoghurt samples supplemented with different concentrations of encapsulated PCEP to plain yoghurt (control). The decrease in viscosity may be attributed to a lower content of casein, because PCEP encapsulated replaced a part of SMP in yoghurt.

\section{CONCLUSION}

At the end of this study encapsulated apple peel extract could be a suitable phenolic compounds for adding to yoghurt. Different encapsulated techniques (freeze-drying and spray-drying) and different homogenization methods (ultrasonication and ultraturrax) were used. The encapsulated PCEP by freeze-drying and homogenized by ultrasonication was more stable in the supplemented yoghurt in comparison with the non-encapsulated PCEP with improved functionality. Encapsulated PCEP had a light effect on the physicochemical properties of the supplemented yoghurt in terms of $\mathrm{pH}$, titratable acidity and viscosity. Therefore, this study suggests that PCEP microcapsules have the potential to be used as a functional food ingredient for healthy yoghurt.

\section{ACKNOWLEDGEMENTS}

The authors express their gratitude to The Scientific and Technological Research Council of Turkey (TÜBİTAK). I would like to acknowledgment everyone who supported me in doing this research. 
El-Messery, T. M., El-Said, M. M., Demircan, E., Ozçelik, B. (2019). Microencapsulation of natural polyphenolic compounds extracted from apple peel and its application in yoghurt. Acta Sci. Pol. Technol. Aliment., 18(1), 25-34. http://dx.doi.org/10.17306/ J.AFS.2019.0597

\section{REFERENCES}

Ades, H., Kesselman, E., Ungar, Y., Shimoni, E. (2012). Complexation with starch for encapsulation and controlled release of menthone and menthol. LWT - Food Sci. Technol., 4(2), 277-288. https://doi.org/10.1016/j. lwt.2011.08.008

Ajila, C. M., Naidu, K. A., Bhat, S. G., Prasada, S. (2007). Bioactive compounds and antioxidant potential of mango peel extract. Food Chem., 105, 982-988. https://doi. org/10.1016/j.foodchem.2007.04.052

AOAC (2000). Official methods of analysis. Arlington, VA: Association of Official Analytical Chemists. https://doi. org/10.1002/0471740039.vec0284

Balázs, A., Tóth, M., Blazics, B., Héthelyi, E., Szarka, S., Ficsor, E., ..., Blázovics, A. (2012). Investigation of dietary important components in selected red fleshed apples by GC-MS and LC-MS. Fitoterapia, 83, 1356-1363. https://doi.org/10.1016/j.fitote.2012.04.017

Bueno, J. M., Ramos-Escudero, F., Saez-Plaza, P., Munoz, A. M., Navas, M. J., Asuero Crit, A. G. (2012). Analysis and antioxidant capacity of anthocyanin pigments. Part 1. General considerations concerning polyphenols and flavonoids. Rev. Anal. Chem., 42, 102-125. https:// doi.org/10.1080/10408347.2011.632312

Chen, Q., Zhong, F., Wen, J., McGillivray, D., Quek, Y. (2013). Properties and stability of spray-dried and freeze-dried microcapsules co-encapsulated with fish oil, phytosterol esters, and limonene. Dry Technol., 31, 707-716. https://doi.org/10.1080/07373937.2012.7555 41

Chung, J., Chu, R., Park, H., Jeng, S., Kang, S. (2010). Influence of the addition of MACA hot water extract on the quality and antioxidant activity of yoghurt. Korean J. Food Culture, 25, 334-341.

Delmas, T., Piraux, H., Couffin, C., Texier, I., Vinet, F., Poulin, P., ..., Bibette, J. (2011). How to prepare and stabilize very small nanoemulsions. Langmuir, 27(5), 1683-1692. https://doi.org/10.1021/la104221q

Dickinson, E. (2003). Hydrocolloids at interfaces and the influence on the properties of dispersed systems. Food Hydrocoll., 17, 25-39. https://doi.org/10.1016/s0268005x(01)00120-5

Do Espírito Santo, F., Franco, K., Capucci, P., Oliveira, G., Giglio, H. (2013). Comparison between freeze and spray drying to obtain powder Rubrivivax gelatinosus biomass. Food Sci. Technol., 33, 47-51. https://doi. org/10.1590/s0101-20612013005000008
Fang, Z., Bhandari, B. (2010). Encapsulation of polyphenols - a review. Trends Food Sci. Technol., 21, 510-523. https://doi.org/10.1016/j.tifs.2010.08.003

Fernandes, B., Borges, V., Botrel, A. (2014). Gum arabic/ starch/maltodextrin/inulin as wall material on the microencapsulation of rosemary essential oil. Carbohyd. Polym., 101, 524-532. https://doi.org/10.1016/j.carbpol.2013.09.083

Ferreira, O., Otero, L., Vidal-Torrado, P., Macías, M. (2007a). Effects of bioturbation by root and crab activity on iron and sulfur biogeochemistry in mangrove substrate. Geoderma, 142, 36-46. https://doi.org/10.1016/j. geoderma.2007.07.010

Fox, P. F., McSweeney, H. (1998). Physical properties of milk. In P. F. Fox, P. L. H. McSweeney (Eds.), Dairy chemistry and biochemistry (pp. 437-462). London: Blackie Academic and Professional. https://doi. org/10.1007/978-3-319-14892-2_8

Gharsallaoui, A., Roudaut, G., Chambin, O., Voilley, A., Saurel, R. (2007). Applications of spray-drying in microencapsulation of food ingredients: An overview. Food Res. Int., 40, 1107-1121. https://doi.org/10.1016/j. foodres.2007.07.004

Grigoras, G., Destandau, E., Fougère, L., Elfakir, C. (2013). Evaluation of apple pomace extracts as a source of bioactive compounds. Ind. Crops Prod., 49, 794-804. https://doi.org/10.1016/j.indcrop.2013.06.026

Hashim, B., Khalil, H., Afifi, S. (2009). Quality characteristics and consumer acceptance of yogurt fortified with date fiber. J. Dairy Sci., 92, 5403-5407. https://doi. org/10.3168/jds.2009-2234

Jakobek, L., García-Villalba, R., Tomás-Barberán, A. (2013). Polyphenolic characterisation of old apple varieties from Southeastern European region. J. Food Compos. Anal., 31, 199-211. https://doi.org/10.1016/j. jfca.2013.05.012

Kailasapathy, K., Chin, J. (2000). Survival and therapeutic potential of probiotic organisms with reference to Lactobacillus acidophilus and Bifidobacterium spp. Immunol. Cell Biol., 78(1), 80-88. https://doi.org/10.1046/j.14401711.2000.00886.x

Khazaei, K., Jafari, S., Ghorbani, M., Kakhki, A. (2014). Application of maltodextrin and gum Arabic in microencapsulation of saffron petal's anthocyanins and evaluating their storage stability and color. Carbohydr. Polym., 105, 57-62. https://doi.org/10.1016/j.carbpol.2014.01.042

Kumaran, A., Karunakaran, J. (2006). Antioxidant and free radical scavenging activity of an aqueous extract of 
Coleus aromaticus. Food Chem., 97, 109-114. https:// doi.org/10.1016/j.foodchem.2005.03.032

Leccese, A., Bartolini, S., Viti, R. (2009): Antioxidant properties of peel and flesh in 'GoldRush' and 'Florina' scab-resistant apple (Malus domestica) cultivars. New Zeal. J. Crop Hort. Sci., 37, 71-78. https://doi. org/10.1080/01140670909510251

Lee, W., Kim, J., Lee, J., Lee, Y. (2003). Cocoa has more phenolic phytochemicals and a higher antioxidant capacity than teas and red wine. J. Agric. Food Chem., 51, 7292-7295. https://doi.org/10.1021/jf0344385

Pastene, E., Troncoso, M., Figueroa, G., Alarcon, J., Speisky, H. (2009). Association between polymerization degree of apple peel polyphenols and inhibition of Helicobacter pylori urease. J. Agric. Food Chem., 57, 416424. https://doi.org/10.1021/jf8025698

Rai, S., Wahile, A., Mukherjee, K., Saha, P., Mukherjee, K. (2006). Antioxidant activity of Nelumbo nucifera (sacred lotus) seeds. J. Ethnopharmacol., 104, 322-327. https://doi.org/10.1016/j.jep.2005.09.025

Ramírez, J., Giraldo, I., Orrego, E. (2015). Modeling and stability of polyphenol in spray-dried and freeze-dried fruit encapsulates. Powder Technol., 277, 89-96. https:// doi.org/10.1016/j.powtec.2015.02.060

Sahin-Nadeem, H., Dinçer, C., Torun, M., Topuz, A., Özdemir, F. (2013). Influence of inlet air temperature and carrier material on the production of instant soluble sage (Salvia fruticosa Miller) by spray drying. LWT - Food Sci. Technol., 52, 31-38.

Silva, I., Stringheta, C., Teófilo, F., Dliveira, N. (2013). Parameter optimization for spray-drying microencapsulation of jaboticaba (Myrciaria jaboticaba) peel extracts using simultaneous analysis of responses. J. Food Eng., 117(4), 538-544. https://doi.org/10.1016/j.jfoodeng.2012.08.039

Sun-Waterhouse, D., Nair, S., Wibisono, R., Wadhwa, S., Massarotto, C., Hedderley, I., ..., Corrigan, V. (2010). Insights into smoothies with high levels of fibre and polyphenols: factors influencing chemical, rheological and sensory properties. World Acad. Sci. Eng. Technol., 65, 276-285. https://doi.org/10.1007/s11947-013-1091-y

Sun-Waterhouse, D., Zhou, J., Wadhwa, S. (2012a). Effects of adding apple polyphenols before and after fermentation on the properties of drinking yoghurt. Food Bioproc. Technol., 5(7), 2674-2686. https://doi.org/10.1007/ s11947-011-0563-1

Sun-Waterhouse, D., Penin-Peyta, L., Wadhwa, S., Waterhouse, G. (2012b). Storage stability of phenolic-fortified avocado oil encapsulated using different polymer formulations and co-extrusion technology. Food Bioproc. Technol., 5(8), 3090-3102. https://doi.org/10.1007/ s11947-011-0591-x

Sun-Waterhouse, D., Zhou, J., Wadhwa, S. (2013a). Drinking yoghurts with berry polyphenols added before and after fermentation. Food Control, 32, 450-460. https:// doi.org/10.1016/j.foodcont.2013.01.011

SPSS (1999). SPSS for Windows. Release 10.0 (27 October 1999). Standard version. https://doi.org/10.1007/978-3322-92004-1_1

Suárez, B., Álvarez, L., García, D., del Barrio, G., Lobo, P., Parra, F. (2010). Phenolic profiles, antioxidant activity and in vitro antiviral properties of apple pomace. Food Chem., 120, 339-342. https://doi.org/10.1016/j.foodchem.2009.09.073

Veeriah, S., Hofmann, T., Glei, M., Pool-Zobel, L. (2007). Apple polyphenols and products formed in the gut differently inhibit survival of human cell lines derived from colon adenoma (LT97) and carcinoma (HT29). J. Agric. Food Chem., 55(8), 2892-2900. https://doi.org/10.1021/ jf063386r

Vieira, K., Borges, C., Copetti, C., Gonzaga, V., Nunes, C., Fett, R. (2009). Activity and contents of polyphenolic antioxidants in the whole fruit, flesh and peel of three apple cultivars. Arch. Latinoam. Nutr., 59(1), 101-106.

Wollgast, J., Anklam, E. (2000). Review on polyphenols in Theobroma cacao: changes in composition during the manufacture of chocolate and methodology for identification and quantification. Food Res. Inter., 33, 423-447. https://doi.org/10.1016/s0963-9969(00)00068-5 